\title{
A VISÃO DA SOCIEDADE PARA OS PROFISSIONAIS COM FORMAÇÃO EAD: A QUEBRA DE UM PARADIGMA
}

\author{
LA VISIÓN DE LA SOCIEDAD PARA PROFESIONALES CON \\ FORMACIÓN EAD: LA RUPTURA DE UN PARADIGMA
}

\author{
THE VISION OF SOCIETY FOR PROFESSIONALS WITH EAD \\ TRAINING: THE BREAKING OF A PARADIGM
}

\author{
João Luiz Coelho RIBAS ${ }^{1}$ \\ Izabelle Cristina GARCIA RODRIGUES ${ }^{2}$ \\ Ivana de FRANÇA GARCIA ${ }^{3}$ \\ Vera Lucia PEREIRA DOS SANTOS ${ }^{4}$
}

RESUMO: A metodologia de ensino presencial é considerada como tradicional, por isso, pessoas que desconhecem as estratégias do Ensino a Distância (EaD) podem subjugar essa modalidade e assim ter uma visão distorcida e preconceituosa dos profissionais formados nesta modalidade. Com isso, o presente estudo tem como objetivo analisar a visão da sociedade com relação ao profissional da área da saúde com formação de cursos EaD. Além de verificar se as empresas contratam profissionais com formação (graduação e pós) $\mathrm{EaD}$ o estudo engloba se as pessoas têm interesse em obter certificados de cursos da modalidade $\mathrm{EaD}$ e a percepção que os profissionais tem de cursos $\mathrm{EaD}$ no desempenho de sua carreira. A metodologia utilizada foi do tipo quantitativa com caráter exploratório. Por meio desse estudo foi possível verificar que a sociedade está mais suscetível ao ensino na modalidade EAD. A maioria dos entrevistados não mostraram preconceito com profissionais formados nessa modalidade, e ainda confirmaram que que já buscaram informações sobre cursos EAD. Além disso, apontaram ter grande interesse em realizar cursos na modalidade EAD. Assim, pode-se confirmar a tendência da expansão de profissionais com formação EAD, fato que se tornará cada vez mais comum nas empresas.

PALAVRAS-CHAVE: Ensino a distância. Saúde. Educação. Mercado de trabalho.

RESUMEN: La metodología de la enseñanza cara a cara se considera tradicional,

${ }^{1}$ Universidade Positivo (Up), Curitiba - PR - Brasil. Docente do Centro Universitário Uninter e da Universidade Positivo. Doutor em Farmacologia pela Universidade Federal do Paraná. E-mail: jlcribas@yahoo.com.br.

2 Centro Universitário Internacional Uninter (Cuiu), Curitiba - PR - Brasil. Docente do Centro Universitário Uninter. Especialista em Mba em Gestão Hospitalar pelo Centro Universitário Uninter. Email: izabelle.r@uninter.com.

3 Centro Universitário Internacional Uninter (Cuiu), Curitiba - PR - Brasil. Docente do Centro Universitário Uninter. Especialista em Mba em Gestão Hospitalar pelo Centro Universitário Uninter. Email: ivana.g@uninter.com.

4 Centro Universitário Internacional Uninter (Cuiu), Curitiba - PR - Brasil. Docente do Centro Universitário Uninter. Mestre em Morfologia pela Universidade Federal do Paraná. E-mail: vera.s@uninter.com.

RPGE- Revista on line de Política e Gestão Educacional, Araraquara, v.21, n.esp.3, p. 1598-1610, dez., 2017. 
por las personas que no conocen las estrategias de Educación a Distancia (EaD) pueden subyugar esta modalidad y así tener una visión distorsionada y prejuiciosa de los profesionales capacitados en esta modalidad. Con esto, el presente estudio tiene como objetivo analizar la visión de la sociedad con respecto al profesional de la salud con la formación de cursos de EaD. Además de verificar si las empresas contratan a profesionales con formación (licenciatura y postgrado) EaD el estudio abarca si las personas están interesadas en obtener certificados de cursos de la modalidad EaD y la percepción que los profesionales tienen de los cursos EaD en el desempeño de su carrera. La metodología utilizada fue del tipo cuantitativo con carácter exploratorio. A través de este estudio, se pudo verificar que la sociedad es más susceptible a la enseñanza en la modalidad EaD. La mayoría de los entrevistados no mostró prejuicios con los profesionales capacitados en esta modalidad, y aún confirmó que ya han buscado información sobre los cursos de EaD. Además, indicaron que tenían un gran interés en tomar cursos en la modalidad EaD. Así, se puede confirmar la tendencia de la expansión de los profesionales con formación EaD, un hecho que será cada vez más común en las empresas

PALABRAS CLAVE: Educación a distancia. Salud. Educación. Mercado de trabajo.

ABSTRACT: The methodology of face-to-face teaching is considered as traditional, so people who do not know the strategies of Distance Learning (EaD) can subjugate this modality and thus have a distorted and prejudiced view of the professionals trained in this modality. With this, the present study aims to analyze the society's vision regarding the health professional with the formation of EaD courses. In addition to verifying whether companies hire professionals with training (undergraduate and postgraduate) EaD the study encompasses whether people are interested in obtaining certificates of courses of the EAD mode and the perception that professionals have of EAD courses in the performance of their career. The methodology used was of the quantitative type with an exploratory character. Through this study it was possible to verify that the society is more susceptible to teaching in the EAD modality. Most of the interviewees did not show prejudice with professionals trained in this modality, and still confirmed that they have already sought information about EAD courses. In addition, they indicated that they had great interest in taking courses in the EAD modality. Thus, it can be confirmed the trend of the expansion of professionals with EAD training, a fact that will become increasingly common in companies

KEYWORDS: Distance education. Health. Education. Labor market.

\section{Introdução}

A educação a distância é uma modalidade de ensino, cujo professores e alunos não estão conectados fisicamente. As aulas, bem como as interações com entre os atores envolvidos, são realizadas por meios tecnológicos comunicação. A Educação a distância está presente em todos os níveis de educação, desde a básica até a formação superior, como pós-graduação (BRASIL, 2016).

RPGE- Revista on line de Política e Gestão Educacional, Araraquara, v.21, n.esp.3, p. 1598-1610, dez., 2017. 
A Educação a Distância $(\mathrm{EaD})$ tem o importante papel de democratizar a educação no país. Porém, mesmo sendo uma modalidade que existe há aproximadamente 150 anos, ainda pode ser considerada recente, pois houve uma grande demora no seu reconhecimento e regulamentação. No Brasil, por exemplo, ocorreu somente em 2005 com o Decreto n 5.622 (CORREAA; SANTOS, 2009; GOMES, 2013).

Inicialmente, o Ensino a Distância $(\mathrm{EaD})$ era feito por correspondência, onde apostilas com exercícios eram enviados pelo correio, posteriormente adotaram-se os modelos com a utilização de rádio, televisão e enfim a internet. $\mathrm{O}$ crescimento de instituições e cursos com essa modalidade ocorreu a partir da publicação da Lei de Diretrizes e Bases da Educação Nacional (LDB), nº 9.394 de dezembro de 1996, que menciona que o poder público deve expandir a educação, porém essa modalidade ainda recebia um parecer de educação experimental e com um caráter precário, o que faz com que para alguns seja uma forma educacional inferior (GOMES 2013; LEMGRUBER, S/D).

A modalidade que surgiu como uma forma de universalização do ensino, essencialmente para aqueles que não tinham condições de frequentar instituições de forma presencialmente, por problemas geográficos, de saúde, entre outros, hoje se consolida como mais uma alternativa de ensino para toda a sociedade. Isto pode ser confirmado pelo aumento no número de alunos matriculados em cursos na metodologia a distância do ano de 2013 (692.279) para o ano de 2015 (796.057) (ABED, 2013, 2015).

Os cursos nesta modalidade têm se expandido de tal forma que as instituições preveem mais investimentos a cada ano, além da ampliação da rede de instituições que ofertam os cursos $\mathrm{EaD}$ (ABED, 2015).

Mas para Netto e Giraffa (2012) grande parte dos professores que atuam nas universidades atualmente são formados pelo método presencial e orientam seus alunos a seguirem essa modalidade, pois “desconhecem as estratégias didáticas específicas para a modalidade EaD”. A ignorância sobre um fato pode trazer a falta de confiança e assim construir uma visão negativa desta modalidade. O que impacta diretamente nas iniciativas de ampliação do acesso à educação da população, principalmente daquelas pessoas que por diversos motivos não podem frequentar instituições convencionais de educação (SILVA et al., 2015; NETTO; GIRAFFA, 2012).

Contudo, Santos (2012) menciona que nem todas as pessoas estão aptas a realizar um curso EAD, pois o perfil do aluno será um diferencial para que se obtenha 
um bom resultado, pois o fato dos alunos não se adaptarem a metodologia de ensino a distância resulta em falta de confiança para exercer sua profissão e se inserirem no mercado de trabalho. Para estes alunos o ensino a distância pode ser visto como de má qualidade. Assim, o perfil dos alunos torna-se um fator essencial para que se obtenha sucesso na modalidade EAD. Os interessados nos cursos de ensino à distância devem ter habilidades como "autodisciplina, automotivação, responsabilidade e capacidade de gerenciar bem o seu próprio tempo", além disso devem interagir com seus professores, tutores e colegas, mesmo que não tenha um contato visual e presencial com essas pessoas, pois isso poderá auxilia-lo na busca de resoluções de eventuais problemas e dificuldades. Diferentemente do ensino presencial, onde o aluno é direcionado pelo professor (SERAFINI, 2012; LESSA, 2010).

No entanto, apesar da grande evolução do ensino EAD pautado na qualidade ainda se observa pré-conceitos a essa modalidade de ensino, mesmo após 11 anos da sua regulamentação no Brasil. Esse preconceito com os profissionais formados nesta modalidade se denota principalmente, na área da saúde.

Diante disso, o objetivo desse estudo foi analisar a visão da sociedade com relação ao profissional da área da saúde com formação de cursos $\mathrm{EaD}$, verificando se as empresas contratam profissionais com essa formação (graduação e pós) juntamente com a percepção que os profissionais tem dessa modalidade no desempenho de sua carreira.

\section{Materiais e métodos}

Trata-se de uma pesquisa do tipo quantitativa com caráter exploratório, de nível nacional. A coleta de dados foi realizada por meio da aplicação de um questionário disponibilizado on line, por meio do Google docs ofline.). O questionário, que contém duas partes, foi direcionado à diretores, presidentes e gestores de Recursos Humanos de empresas que atuam na área da saúde, além de profissionais dessa mesma área. A primeira parte do questionário contou com 12 perguntas que visaram descobrir a visão dos profissionais da área da saúde com relação aos cursos $\mathrm{EAD}$, enquanto a segunda parte, contém sete perguntas e foi disponibilizado apenas para os entrevistados que responderam que possuiam alguma influencia na contratação de profissionais, visando buscar informações sobre a percepção dos gestores com relação aos profissionais com formação EAD. 
Os critérios de inclusão para participar da pesquisa foram: profissionais e empresas que tivessem algum envolvimento com a área da saúde; profissionais que estivem ativos no mercado de trabalho. Para participar da segunda parte do questionário o critério de inclusão foi que o profissional tivesse alguma influencia sobre o processo de contratação.

Já os critérios de exclusão foram: profissionais e empresas sem relação com a área da saúde; pessoas que estão fora do mercado de trabalho. Para participar da segunda parte do questionário o critério de exclusão foi que o profissional não tenha nenhuma influencia sobre o processo de contratação.

\section{Resultados e discussão}

O ensino a distância veio como uma alternativa para auxiliar as pessoas que não tinham condições de estudar de forma presencial e agora se apresenta como uma realidade para toda a sociedade, inclusive em expansão.

Comparando-se os anos de 2012 e 2013 nota-se que houve um crescimento no número de cursos, incentivos financeiros e de matrículas em cursos corporativos EAD e analisando os anos de 2015 e 2016, nota-se o mesmo crescimento. Devido a esta visibilidade e expansão do ensino a distância surge a preocupação com a inserção desses alunos no mercado de trabalho, por isso, o estudo buscou questionar os entrevistados sobre o nível de interesse nos cursos na modalidade a distância, bem como a confiabilidade no ensino e nos profissionais formados pelo EAD, possibilitando assim responder ao objetivo do estudo: a visão da sociedade com relação ao profissional da área da saúde com formação de cursos $\mathrm{EaD}$.

O total de profissionais que responderam a pesquisa foi de 338 pessoas. Destas 208 foram habilitadas para a segunda parte da pesquisa, que incluia questionamentos para os profissionais que tivessem alguma influência na contratação de funcionário em suas empresas.

Dos profissionais que responderam a pesquisa, eles estão divididos em relação a faixa etária e região de localização profissional da seguinte forma: faixa etária de 30-39 anos (41\%), são residentes nas regiões sul e sudeste (46\% e $26 \%$ respectivamente) e 54\% dos entrevistados já possui Especialização ou MBA, sendo que a formação é diversificada, porém as áreas de humanidades (46\%) e saúde (34\%) as mais 
frequentes.Corroborando com os resultados, Santana, et al. (2016) aponta que em seu estudo a faixa etária dos trabalhadores da àrea da saúde é de 31 a 40 anos, e o Instituto de Pesquisa Econômica Aplicada (IPEA) aponta que a maior faixa da população economicamente ativa está presente nas regiões sul e sudeste.

Entre os cargos exercidos pelos entrevistados destaca-se o papel de líder (diretor, coordenador e gestor) indicado por $31 \%$ dos profissionais. Os demais entrevistados atuam como técnicos, operadores ou supervisores.

A relação geral dos questionamento e a porcentagem de respostas, podem ser visualizadas de forma integrada na tabela 1 .

Tabela 1: Integração questionamentos e porcentagem das respostas

Questionamento: Você já buscou informações de sobre cursos na metodologia a distância?

$\begin{array}{lc}\text { Sim } & \text { Não } \\ 92 \% & 8 \%\end{array}$

Questionamento: Você já realizou algum curso na metodologia a distância?

Não

$18 \%$

\section{Apenas}

cursos de pósgraduação

$48 \%$
Indiferente a formação

$34 \%$

Questionamento: Você realizaria um curso na modalidade a distância, caso a empresa em que atua firmasse uma parceria com uma instituição de Ensino a distância?

$$
\text { Sim, }
$$

Sim, somente se obtivesse indiferente de algum benefício.

$$
\text { benefícios }
$$

concedidos.

\section{Não.}

$19 \%$

$74 \%$

$7 \%$

Questionamento: Na empresa onde atua há algum profissional com formação na modalidade de ensino a distância?

$\begin{array}{lcc}\text { Sim } & \text { Não } & \text { Não sei } \\ 53 \% & 21,2 \% & 25,8 \%\end{array}$

Questionamento: Como você avalia seu nível de confiabilidade nos cursos à distância, na área da saúde?

$\begin{array}{ccc}\text { Alto } & \begin{array}{c}\text { Intermed } \\ \text { iário }\end{array} & \text { Baixo } \\ 27 \% & 54 \% & 19 \%\end{array}$

Questionamento: Você julga que o curso, na área da saúde, na modalidade a distância tenha a mesma credibilidade que o curso presencial?

Sim Não

RPGE- Revista on line de Política e Gestão Educacional, Araraquara, v.21, n.esp.3, p. 1598-1610, dez., 2017. 
Questionamento: Qual seu nível de influência na contratação de profissionais no setor em que atua?

\begin{tabular}{|c|c|c|c|}
\hline Alto & $\begin{array}{l}\text { Intermed } \\
\text { iário }\end{array}$ & Baixo & enhum \\
\hline $17,3 \%$ & $29,9 \%$ & 14,8 & $8 \%$ \\
\hline
\end{tabular}

Questionamento: Qual o seu nível de confiabilidade na formação de profissionais, da área da saúde, de cursos de ensino a distância $(\mathrm{EaD})$ ?

$\begin{array}{ccc}\text { Alto } & \text { Intermed } & \text { Baixo } \\ 29 \% & \text { iário } & 21 \%\end{array}$

Questionamento: Você contrataria um profissional com formação na modalidade de ensino a distância $(\mathrm{EaD})$ para atuar na área da saúde?

$\begin{array}{ll}\text { Sim } & \text { Não } \\ 74 \% & 26 \%\end{array}$

Questionamento: O fato do profissional da área da saúde ter sua formação na modalidade a distância, muda sua intenção de contratação?

$$
\begin{array}{ll}
\text { Sim } & \text { Não } \\
37 \% & 63 \%
\end{array}
$$

Questionamento: Você aceitaria ser atendido por um profissional graduado na área da saúde com formação à distância?

$\begin{array}{ccc}\text { Sim } & \text { Não } & \begin{array}{c}\text { Somente se não tivesse outra } \\ \text { opção. }\end{array} \\ 67 \% & 11,80 \% & 20,90 \%\end{array}$

Questionamento: Você aceitaria ser atendido por um profissional da área da saúde que foi graduado na modalidade presencial, com especialização na modalidade à distância?

\begin{tabular}{ccc} 
Sim & Não & $\begin{array}{c}\text { Somente se não tivesse outra } \\
\text { opção. }\end{array}$ \\
$90 \%$ & $2,40 \%$ & $7,60 \%$ \\
\hline
\end{tabular}

Fonte: autores

Os entrevistados foram questionados se já buscaram informações sobre cursos na metodologia a distância. Apenas $8 \%$ responderam que não. Entre aqueles que responderam sim, a grande maioria já havia procurado informações sobre as áreas da saúde e humanidades (41\% e $31 \%$ respectivamente). Devido a flexibilidade e a internacionalização do método de ensino EAD, a busca por cursos nessa modalidade tem se expandido, bem como o número de instituições que oferecem cursos nessa modalidade (SOUSA; VARGAS; MASSENSINI, 2014). Contudo, muitas vezes o preconceito e a falta de conhecimento sobre a qualidade do ensino, faz com que as

RPGE- Revista on line de Política e Gestão Educacional, Araraquara, v.21, n.esp.3, p. 1598-1610, dez., 2017. 
pessoas não se matrículem em cursos EAD (MELO, 2016), conforme demonstrado no estudo presente, onde aproximadamente $20 \%$ dos entrevistados nunca realizaram cursos na modalidade a distância. Entre aqueles que realizaram, 49\% fizeram algum curso de pós graduação enquanto os demais fizeram cursos de graduação ou extensão.

Sobre o questionamento se os entrevistados realizariam um curso na metodologia a distância na área da saúde, apenas $18 \%$ responderam que não. A maioria, $48 \%$ respondeu que realizaria apenas cursos de pós-graduação e para $34 \%$ é indiferente a formação. A área da saúde encontra-se numa situação degradante e carente de aperfeiçoamento profissional, sendo assim, o ensino a distância vem como uma alternativa para qualificar esses profissionais, princpalmente, quando se relaciona a formação EAD à educação permanente. A abertura para a inserção do ensino EAD na saúde se deu devido a ampliação do termo (COSTA et al, p. 48, 2012).

Os entrevistados foram questionados ainda se realizariam um curso na modalidade a distância, caso a empresa em que atua firmasse uma parceria com uma instituição de ensino a distância. Para a grande maioria (74\%) a concessão de benefícios é indiferente. Responderam não $7 \%$ e $19 \%$ responderam que realizariam um curso na modalidade EAD somente com concessão de benefícios. Além dessa informação, $53 \%$ dos entrevistados relataram que há algum profissional com formação na modalidade de ensino a distância na empresa onde atuam. Conforme afirma Araújo et al. (2013, p. 639) a sedimentação do ensino EAD no mercado de trabalho está relacionada a "postura dos gestores e da equipe de profissionais, que devem promover a quebra de paradigmas". Logo, de acordo com os resultados da pesquisa, nota-se que houve uma mudança no comportamento dos profissionais e que atualmente há uma grande abertura para capacitações na modalidade EAD.

Os entrevistados foram questionados também sobre o nível de confiança nos cursos à distância na área da saúde. A maioria, 54\%, indicou um nível intermediáro de confiança, enquanto $27 \%$ consideram alto e $19 \%$ baixo nível. Comparando a credibilidade dos cursos na área da saúde nas modalidades a distância e presencial, 52\% consideram que não há a mesma credibilidade. Essa falta de confiança está atrelada "ao fato de que há instituições que disponibilizam esse tipo de serviço e estão preocupadas unicamente com sua expansão e com o consequente aumento do número de matrículas, quando deveriam prezar pela qualidade do conteúdo oferecido". Porém, como é o sistema presencial é mais tradicional as pessoas tendem a aceitar com mais facilidade (MELO, 2016)

RPGE- Revista on line de Política e Gestão Educacional, Araraquara, v.21, n.esp.3, p. 1598-1610, dez., 2017. 
A segunda parte do questionário foi disponibilizada apenas para as pessoas que responderam ter algum tipo de influencia na contratação de colaboradores $(62 \%)$, sendo assim, 38\% do total dos entrevistados foram excluídos das perguntas, pois responderam que não tinham nenhuma influência.

Quando questionados sobre o nível de confiabilidade na formação a distância dos profissionais da área da saúde, 29\% consideraram alta, 50\% intermediária e apenas $21 \%$ baixa.

Entre esses entrevistados $74 \%$ afirmaram que contratariam um profissional com formação a distância para atuar na área da saúde, demonstrando a confiança nos profissionais da $\mathrm{EaD}$. O fato do profissional da área da saúde ter sua formação na modalidade a distância não muda a intenção de contratação para $63 \%$ dos entrevistados.

Segundo o Ministério da Saúde, aprendizagem significativa é o processo de aprendizagem que propicia a construção de conhecimentos a partir dos saberes prévios dos sujeitos articulados aos problemas vivenciados no trabalho (BRASIL, 2014).

A educação da equipe multiprofissional da saúde requer empenho para o aprimoramento de métodos educativos que atinjam com eficácia esses profissionais (PEIXOTO et al., 2013).

Devido a flexibilidade, o ensino na modalidade a distância tem se mostrado uma realidade em expansão, até mesmo em instituições federais de ensino, conhecidas por serem tradicionais em seus métodos. A maior preocupação com o ensino à distância está relacionada aos profissionais que estão sendo inseridos no mercado de trabalho, principalmente quando esses são responsáveis por vidas, como no caso dos cursos pertencentes a área da saúde (PRETI, 1998; CARNEIRO; CARNEIRO; GIARDINI, 2011). Contudo, essa preocupação não se reflete na sociedade, pois, os resultados deste estudo, apontaram uma grande aceitação da sociedade com a inserção da Educação a Distância, além de não apresentarem preconceito com estudantes e profissionais formados nessa modalidade.

A EAD é um meio apropriado e importante para atender a grandes contingentes de alunos de forma mais efetiva que outras modalidades, e sem riscos de reduzir a qualidade dos serviços oferecidos em decorrência da ampliação da clientela atendida (OLIVIERA, 2007).

Os entrevistados foram questionados como avaliam um profissional que buscou elevação de cargo realizando um curso pós-graduação na modalidade EaD. As respostas estão indicadas na Figura 1.

RPGE- Revista on line de Política e Gestão Educacional, Araraquara, v.21, n.esp.3, p. 1598-1610, dez., 2017. 
Figura 1: Avaliação dos profissionais que buscam formação na modalidade EAD

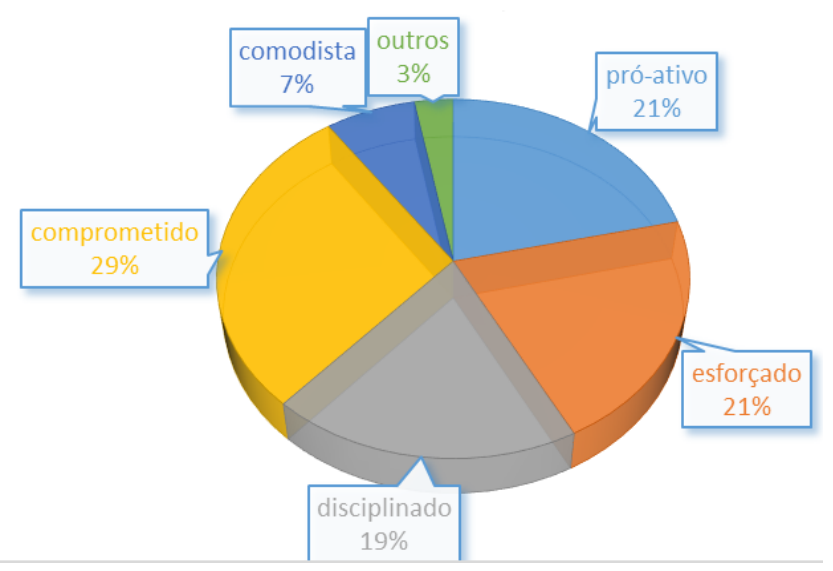

Fonte: autores

Sobre ser atendido por um profissional graduado na área da saúde com formação à distância, 67\% dos pesquisados responderam que aceitariam. Os entrevistados demonstraram uma grande aceitação dos profissionais com formação EAD. A grande maioria dos entrevistados, 90\%, reponderam que aceitariam ser atendidos por um profissional da área da saúde graduado na modalidade presencial e com especialização na modalidade à distância

A área de saúde necessita cada vez mais de profissionais qualificados para fazer frente aos desafios da saúde no país e o ensino a distância vem despontando como um importante ponto estratégico para a qualificação de profissionais no Brasil (PAIM; GUIMARÃES, 2009; ALVES; VELOSO, 2009; ANDERSON; RODRIGUES, 2011).

Para manter os profissionais da saúde em constante atualização e superar as novas tendências do mercado de trabalho é necessário mantê-los em constante processo educativo em seu ambiente de trabalho (NIETSCHE, 2009).

Preti já em seu estudo de 1998, apontou que um dos dilemas da época era o número de analfabetos, semi-analfabetos e chefes de família sem instrução. O seu estudo foi realizado quando a discussão da Lei de Diretrizes e Bases da Educação Nacional (LDB) estava em alta, onde o Governo Federal na tentativa de democratizar a educação aprovou, em 1999, a lei que sugeria a expansão da educação para a população. Analisando os períodos de 1998, quando Preti publicou seu estudo e os dias atuais, nota-se que inicialmente a preocupação era com a formação da população e a promoção da educação. Atualmente esse problema transformou-se em qualidade de educação, que posteriormente promulga-se em qualidade profissional. 


\section{Considerações finais}

Após 11 anos da regularização do ensino na modalidade a distância, pode-se verificar pelo presente estudo que a sociedade está receptiva para os profissionais que realizaram cursos nessa área. A grande maioria dos entrevistados (74\%) demonstraram confiabilidade no ensino a distância, pois responderam que contratariam profissionais de saúde que possuem formação no ensino EAD.

Além do mais, a confiança nessa metodologia se evidenciou quando $67 \%$ dos entrevistados afirmaram que aceitariam ser atendidos por profissionais da saúde com formação EAD e o índice é ainda maior quando o profissional possui apenas a especialização nessa modalidade. Isto mostra a mudança no comportamento da sociedade, que anteriormente via o ensino a distância como uma alternativa apenas para as pessoas que não condições de frequentar cursos presenciais.

Foi possível perceber também que por vezes a falta de conhecimento sobre a qualidade do ensino dessa modalidade, bem como o preconceito e a falta de incentivo são os principais fatores de desistência para se introduzir em um curso EAD.

Em anos anteriores a preocupação era a introdução das pessoas ao ensino e atualmente, após a inserção do estudo a distância mudou o foco, sendo a qualidade o principal. Após tantos anos da homologação dessa modalidade pode-se perceber por meio deste estudo que a qualidade e a confiança estão sendo estabelecidos e conquistados pouco a pouco.

\section{REFERÊNCIAS}

ABED. Associação Brasileira de Ensino a Distância. Censo EAD.BR: Relatório Analítico de Aprendizagem a Distância no Brasil. Curitiba: Intersaberes, 2015.

ALVES, V. S.; VELOSO, R. Sistemas de Educação a Distância: subsídios para a construção do modelo de gestão desta modalidade de ensino no contexto da secretaria de saúde do estado da Bahia. Rev. Baiana Saúde Pública, v. 33, n. 1, p. 86-93, 2009.

ANDERSON, M. I. P.; RODRIGUES, R. D. Formação de especialistas em Medicina de Família e Comunidade no Brasil: dilemas e perspectivas. Rev. Bras. Med. Fam.

Comunidade, Florianópolis, v. 6, n. 18, p. 19-20, 2011.

ARAÚJO, E.M.; OLIVEIRA NETO, J. D.; CAZARINI, E.W.; OLIVEIRA, S.R.M. A gestão da inovação na educação a distância. Gest. Prod., São Carlos, v. 20, n. 3, p. 639651, 2013.

RPGE- Revista on line de Política e Gestão Educacional, Araraquara, v.21, n.esp.3, p. 1598-1610, dez., 2017. 
BRASIL. Ministério da Saúde. Gabinete do Ministro. Portaria no 278, de 27 de fevereiro de 2014. Institui diretrizes para implementação da Política de Educação Permanente em Saúde, no âmbito do Ministério da Saúde (MS). Disponível em: <http://bvsms.saude.gov.br/bvs/saudelegis/gm/2014/prt0278_27_02_2014.html>. Acesso em: 05 de out. 2016.

BRASIL. Ministério de Educação. O que é Educação a Distância. 2016. Disponível em: <http://portal.mec.gov.br/component/content/article?id=12823:o-que-e-educacaoa-distancia>. Acesso em: 15 out. 2016.

CARNEIRO, A. C. G. B.; CARNEIRO, C. A. G. B.; GIARDINI, M. M. A educação a distância e o mercado de trabalho. Disponível em:

<http://www.periodicos.letras.ufmg.br/index.php/ueadsl/article/viewFile/2922/2881>. Acesso em: 23 set. 2016.

CORRÊA, S. C.; SANTOS, L. M. M. Preconceito e educação a distância: atitudes de estudantes universitários sobre os cursos de graduação na modalidade a distância.

Educação Temática Digital, Campinas, v.11, n.1, p.273-297, 2009.

COSTA, M. A.; SANTOS, N. B.; RODRIGUEZ, J. A. F.; BARBOSA, D. S.; SILVA, T. P.; SPILKER, M. J.; COSTA, S. M. M. EAD e saúde: aproximação entre as áreas a partir da experiência de um curso na Fundação Oswaldo Cruz. Fundação Cecierj., Rio de Janeiro, n. 2, p. 47-118, 2012.

DALFOVO, M. S.; LANA, R. A.; SILVEIRA, A. Métodos quantitativos e qualitativos: um resgate teórico. Revista Interdisciplinar Científica Aplicada, Blumenau, v.2, n.4, p.01- 13, Sem II. 2008.

GOMES, L. F. EAD no Brasil: perspectivas e desafios. Avaliação, Campinas, v.18, n. 1, p. 13-22, 2013.

LEMGRUBER, M. S. Educação a Distância: para além dos caixas eletrônicos.

Disponível em:

<http://portal.mec.gov.br/arquivos/conferencia/documentos/marcio_lemgruber.pdf $>$.

Acesso em: Acesso em: 28 set. 2016.

LESSA, S. C. F. Os reflexos da legislação de educação a distância no Brasil. 2010. Disponível em:

<http://www.abed.org.br/revistacientifica/Revista_PDF_Doc/2010/2010_232010234551 .pdf>. Acesso em: 05 out. 2016.

MELO, C. S. Os desafios do ensino a distância no Brasil. 2016. Disponível em: $<$ https://www.projetoredacao.com.br/temas-de-redacao/os-desafios-do-ensino-adistancia-no-brasil/os-desafios-do-ensino-a-distancia-no-brasil-8/49170>. Acesso em: 05 out. 2016.

NETTO, C.; GIRAFFA, L. M. M. Preconceito ou despreparo? Uma investigação acerca da percepção dos docentes de Pedagogia sobre formação de professores na modalidade EAD. IX ANPED SUL. Seminário de Pesquisa em Educação da Região Sul. 2012. 
NIETSCHE, E. A.; BACKES, V. M. S.; FERRAZ, F.; LOUREIRO, L.; SCHMIDT, S. M. S.; NOAL, H. C. Política de educação continuada institucional: um desafio em construção. Rev. Eletr. Enf., v. 11, n. 2, p. 341-8, 2009. Disponível em:

<https://www.fen.ufg.br/revista/v11/n2/v11n2a15.htm>. Acesso em: 10 out. 2016.

OLIVEIRA, M. A. N. Educação à Distância como estratégia para a educação

permanente: possibilidades e desafios. Rev. Bras. Enferm., Brasília, v. 60, n. 5, p. 5859, 2007.

PAIM, M. C.; GUIMARÃES, J. M. M. Importância da formação de docentes em EAD no processo de educação permanente para trabalhadores do SUS na Bahia. Rev. Baiana Saúde Pública, v. 33, n. 1, p. 94-103, 2009.

PRETI, O. Educação a distância e globalização: desafios e tendências. R. Bras. Est. Pedag., Brasília, v. 79, n. 191, p.19-30, 1998.

SANTOS, M. C. O preconceito na educação a distância: a visão dos discentes de um curso de Letras EAD. VI Colóquio Internacional "Educação e

Contemporaneidade". São Cristóvão, SE, 20 a 22 de setembro de 2012.

SERAFINI, A. M. S. A autonomia do aluno no contexto da Educação a Distância.

Educ. foco, Juiz de Fora, v. 17, n. 2, p. 61-82, 2012.

SILVA, R. C.; SANTOS, V. L. P.; MENDES, L. H. S.; LIMA, A. P. W.; GARCIA, I. F. Pós-graduação na área de saúde na modalidade EAD: perfil e dificuldades dos alunos.

Revista Intrersaberes, v. 10, n. 20, p. 1-23, 2015.

SOUSA, P. T.; VARGAS, L. P. M.; MASSENSINI, A. R. Referenciais de qualidade em EAD: a porta para a internacionalização dos cursos em EAD no Brasil - um estudo de caso no SENAI/GOIÁS mediante o benchmarking nos cursos profissionalizantes. Disponível em: <http://www.abed.org.br/hotsite/20-ciaed/pt/anais/pdf/99.pdf >. Acesso em: 05 set. 2016.

\section{Como referenciar este artigo}

RIBAS, João Luiz, Coelho et al. A visão da sociedade para os profissionais com formação EaD: a quebra de um paradigma. Revista on line de Política e Gestão Educacional, Araraquara, v.21, n.esp.3, p. 1598-1610, dez., 2017. ISSN: 1519-9029.

Submetido em: 07/03/2017

Aprovado em: 11/07/2017

RPGE- Revista on line de Política e Gestão Educacional, Araraquara, v.21, n.esp.3, p. 1598-1610, dez., 2017. 